\title{
The Performance and Usability of a Factory-Calibrated Flash Glucose Monitoring System
}

\author{
Timothy Bailey, MD, FACE, FACP, Bruce W. Bode, MD, FACE, \\ Mark P. Christiansen, $\mathrm{MD}^{3}$ Leslie J. Klaff, $\mathrm{MD}^{4}$ and Shridhara Alva, $\mathrm{PhD}^{5}$
}

\begin{abstract}
Introduction: The purpose of the study was to evaluate the performance and usability of the FreeStyle ${ }^{\circledR}$ Libre $^{\mathrm{TM}}$ Flash glucose monitoring system (Abbott Diabetes Care, Alameda, CA) for interstitial glucose results compared with capillary blood glucose results.

Materials and Methods: Seventy-two study participants with type 1 or type 2 diabetes were enrolled by four U.S. clinical sites. A sensor was inserted on the back of each upper arm for up to 14 days. Three factory-only calibrated sensor lots were used in the study. Sensor glucose measurements were compared with capillary blood glucose (BG) results (approximately eight per day) obtained using the BG meter built into the reader (BG reference) and with the YSI analyzer (Yellow Springs Instrument, Yellow Springs, $\mathrm{OH}$ ) reference tests at three clinic visits (32 samples per visit). Sensor readings were masked to the participants.

Results: The accuracy of the results was demonstrated against capillary BG reference values, with $86.7 \%$ of sensor results within Consensus Error Grid Zone A. The percentage of readings within Consensus Error Grid Zone A on Days 2, 7, and 14 was $88.4 \%, 89.2 \%$, and $85.2 \%$, respectively. The overall mean absolute relative difference was $11.4 \%$. The mean lag time between sensor and YSI reference values was $4.5 \pm 4.8 \mathrm{~min}$. Sensor accuracy was not affected by factors such as body mass index, age, type of diabetes, clinical site, insulin administration, or hemoglobin A1c.

Conclusions: Interstitial glucose measurements with the FreeStyle Libre system were found to be accurate compared with capillary BG reference values, with accuracy remaining stable over 14 days of wear and unaffected by patient characteristics.
\end{abstract}

\section{Introduction}

CAPILlARY AND VENOUS BLOOD GLUCOSE (BG) values are typically used as reference to evaluate the accuracy of in vivo sensor devices. ${ }^{1-5}$ Clinical laboratories use venous samples analyzed using a laboratory analyzer, whereas lay users use capillary BG measurements measured using a glucose meter for the calibration of sensors. ${ }^{6-8}$ Glucose concentrations between the capillary and venous samples differ, and therefore the sample type used for calibration versus reference measurement may influence the results of an accuracy evaluation. ${ }^{9,10}$ The FreeStyle ${ }^{\circledR}$ Libre $^{\mathrm{TM}}$ Flash glucose monitoring system (Abbott Diabetes Care, Alameda, CA), hereafter referred to as the "System," is an interstitial glucose monitoring system intended to be a replacement for the capillary BG measurement. Therefore, capillary BG may be considered an appropriate comparator in evaluating the performance and accuracy of this factory-only calibrated System. Additionally, capillary BG provides more reference points and represents real-life accuracy during daily patient use.

\footnotetext{
${ }^{1}$ AMCR Institute, Escondido, California.

${ }^{2}$ Atlanta Diabetes Associates, Atlanta, Georgia.

${ }^{3}$ Diablo Clinical Research, Walnut Creek, California.

${ }^{4}$ Rainier Clinical Research Center, Renton, Washington.

${ }^{5}$ Clinical Affairs, Abbott Diabetes Care, Alameda, California.

This study is registered with ClinicalTrials.gov with clinical trial registration number NCT02073058.

(C) The Author(s) 2015; Published by Mary Ann Liebert, Inc. This Open Access article is distributed under the terms of the Creative Commons Attribution Noncommercial License (http://creativecommons.org/licenses/by-nc/4.0/) which permits any noncommercial use, distribution, and reproduction in any medium, provided the original author(s) and the source are credited.
} 
The System has several features that distinguish it from existing sensor technology. The wired enzyme sensor is calibrated in the factory and therefore requires no user calibration during 14 days of wear. This feature differs from existing sensors, which require multiple fingerstick BG measurements over the life of the sensor for calibration. ${ }^{11,12}$ The entire System's on-body sensor patch worn on the back of the upper arm is disposable after use. The hand-held reader with the built-in FreeStyle Precision BG meter is used to scan the sensor to receive a glucose result along with historic results with a 15 -min frequency for up to $8 \mathrm{~h}$. The $\mathrm{BG}$ readings on the built-in meter are independent of, and do not influence, sensor readings. The System displays trends and alerts on the Reader but does not have real-time alarms, which may provide a good option for individuals who complain of alarm fatigue. ${ }^{11,13}$

The objective of this article is to describe the performance and usability of the System by comparing its scanned sensor results with capillary BG values measured using the built-in $\mathrm{BG}$ meter. Performance against the venous blood reference is provided for comparison.

\section{Materials and Methods}

This prospective, single-arm, clinical study was conducted at four U.S. clinical sites. The protocol and informed consent forms were approved by a central Institutional Review Board, and all subjects provided written informed consent before enrollment in the study.

Study participants inserted and wore the sensor on the back of each upper arm (two sensors total), without any overbandage, for up to 14 days. Three factory-calibrated production sensor lots were used for the study. This number is consistent with the industry practice to demonstrate the performance of reagent systems across multiple production lots.

There were three scheduled in-clinic visits during the 14-day sensor wear period, where venous blood samples were collected every 15 min over an 8 -h period for YSI analyzer (Yellow Springs Instrument, Yellow Springs, $\mathrm{OH}$ ) reference tests. The first in-clinic visit was between Day 1 and 3, the second in-clinic visit was between Day 4 and 9, and the third in-clinic visit was between Day 10 and 14. Twenty-four (of 144) sensors that were dislodged prior to the second in-clinic visit were replaced; sensors that were dislodged after that time were not replaced.

At least eight capillary BG tests, using the BG meter built into the reader, were required to be performed on each day of the sensor wear, both at home and in the clinic. One strip lot was used to minimize lot-to-lot variation. The preferred testing was upon waking, before each meal, an hour after each meal, and at bedtime. Immediately after each BG test, participants obtained a confirmation of a successful sensor scan. Sensor readings were masked to participants, who were asked to maintain their established diabetes management plan. There was no manipulation of the glucose levels of the subjects except for their normal meal and insulin doses. Capillary BG tests coincided with venous YSI samples drawn during in-clinic visits.

A linear mixed model was used to assess sensitivity and mean absolute relative difference (MARD) between insertion sites, with subject as a random effect and insertion site (left arm, right arm) and lot as fixed effects. The lag between the System sensor and YSI reference was evaluated using a model that characterizes delay with a time constant. ${ }^{14}$ Analyses were carried out using SAS version 9.2 software (SAS Institute, Cary, NC).

\section{Results}

Seventy-two of 75 study participants were included in the evaluation. Three participants exited after Visit 1 (two could not comply with study visits, and one had non-study-related severe hypoglycemia prior to sensor insertion with unknown complications). The subject characteristics of the study participants are provided in Table 1.

The real-time glucose level was available for $99.2 \%$ $(25,834 / 26,045)$ of sensor scans, where complete sensor data were transferred to the reader. In total, 13,195 BG and 12,172 YSI reference results were paired with sensor glucose results. Twenty-eight pairs were excluded because the reference glucose result was beyond the BG system's dynamic range (20-500 mg/dL), and 114 pairs were excluded because the sensor result was beyond the System's dynamic range (40$500 \mathrm{mg} / \mathrm{dL}$ ). The percentages of results in Zone A of the Consensus and Clarke Error Grids were $86.7 \%$ and $85.5 \%$, respectively (Fig. 1). The percentages of sensor results in Zones A and B of the Consensus and Clarke Error Grids were $99.7 \%$ and $99.0 \%$, respectively, whereas $86.2 \%$ and $82.8 \%$ of sensor results were within $\pm 15 \mathrm{mg} / \mathrm{dL}$ or $\pm 20 \%$ of $\mathrm{BG}$ reference and venous reference, respectively. Continuous glucose error grid analysis (EGA) versus venous reference showed $96.5 \%(11,232 / 11,640)$ of the data categorized as clinically accurate, and a further $2.4 \%(274 / 11,640)$ were classified as benign errors.

The overall MARD was $11.4 \%$ for sensor results with capillary BG reference. The overall MARD in the clinic alone for sensors' results with capillary BG reference and with YSI reference was $12.1 \%$ and $12 \%$, respectively. A detailed difference analysis against capillary and venous blood reference

\begin{tabular}{|c|c|c|c|}
\hline Characteristic & $M e a n \pm S D$ & Median & Range \\
\hline Age (years) & $46.4 \pm 15.1$ & 48.5 & $18-71$ \\
\hline \multicolumn{4}{|l|}{ Weight } \\
\hline Pounds & $182.2 \pm 42.1$ & 175.8 & $102.0-299.8$ \\
\hline Kilograms & $82.6 \pm 19.1$ & 79.7 & $46.3-136.0$ \\
\hline \multicolumn{4}{|l|}{ Height } \\
\hline Inches & $67.1 \pm 4.3$ & 66.5 & $59-81$ \\
\hline Meters & $1.70 \pm 0.11$ & 1.69 & $1.50-2.06$ \\
\hline Body mass index $\left(\mathrm{kg} / \mathrm{m}^{2}\right)$ & $28.3 \pm 5.3$ & 27.4 & $18.7-47.2$ \\
\hline Years since diagnosis & $23.0 \pm 13.1$ & 22.3 & $2.4-50.6$ \\
\hline $\begin{array}{l}\text { Total number of } \\
\text { injections per day } \\
(n=33 \text { subjects })\end{array}$ & $4.6 \pm 1.1$ & 4 & $3-8$ \\
\hline HbAlc (\%) & $7.8 \pm 1.2$ & 7.8 & $5.5-11.5$ \\
\hline $\begin{array}{l}\text { Number of BG tests } \\
\text { per day }\end{array}$ & $7.4 \pm 1.0$ & 7.7 & $4.0-9.6$ \\
\hline
\end{tabular}

Hemoglobin A1c $(\mathrm{HbA1c})$ levels were measured at the start of the study. The number of tests per day was calculated from the test records on the FreeStyle Libre Reader.

BG, blood glucose. 


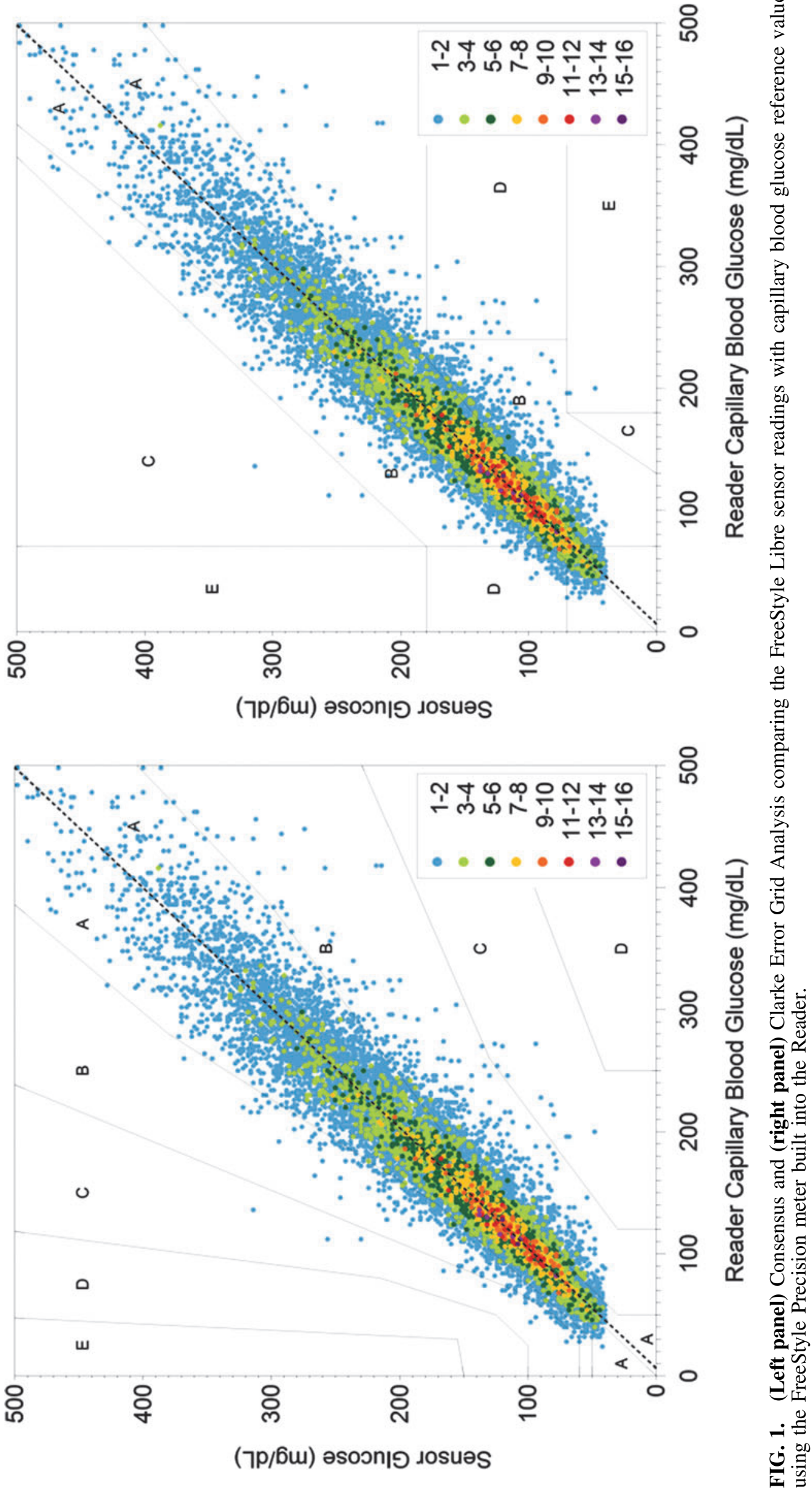


Table 2. Difference Analysis Compared with Capillary and Venous Reference Under Various Conditions

\begin{tabular}{|c|c|c|c|c|c|c|c|c|c|c|}
\hline \multirow{2}{*}{$\begin{array}{l}\text { Reference, glucose } \\
\text { range, parameter }\end{array}$} & \multicolumn{3}{|c|}{ Days $1-14$} & \multicolumn{3}{|c|}{ Days 2-14 } & \multirow{2}{*}{$\begin{array}{c}\text { Day } \\
\text { (7 a.m.- } \\
11 \text { p.m.) }\end{array}$} & \multirow{2}{*}{$\begin{array}{l}\text { Night } \\
(11 \text { p.m. } \\
-7 \text { a.m. })\end{array}$} & \multicolumn{2}{|c|}{$\begin{array}{l}\text { Without hypoglycemia/ } \\
\text { rapid change }^{\mathrm{a}}\end{array}$} \\
\hline & All & Home & Clinic & All & Home & Clinic & & & All & Clinic \\
\hline \multicolumn{11}{|l|}{ Capillary, BG } \\
\hline \multicolumn{11}{|l|}{$<100 \mathrm{mg} / \mathrm{dL}$} \\
\hline $\mathrm{MAD}(\mathrm{mg} / \mathrm{dL})$ & 11.3 & 11.3 & 11.8 & 11.0 & 11.0 & 10.6 & 11.5 & 10.4 & 10.3 & 8.4 \\
\hline$n$ & 2,153 & 1,946 & 207 & 1,985 & 1,813 & 172 & 1,787 & 366 & 905 & 97 \\
\hline \multicolumn{11}{|l|}{$\geq 100 \mathrm{mg} / \mathrm{dL}$} \\
\hline MARD (\%) & 10.7 & 10.5 & 11.8 & 10.2 & 10.2 & 10.4 & 10.8 & 9.9 & 10.2 & 11.1 \\
\hline$n$ & 11,042 & 9,642 & 1,400 & 9,987 & 8,878 & 1,109 & 9,717 & 1,325 & 9,341 & 1,236 \\
\hline \multicolumn{11}{|l|}{ All } \\
\hline$\%$ & 11.4 & 11.3 & 12.1 & 11.0 & 11.0 & 10.7 & 11.5 & 10.8 & 10.4 & 11.0 \\
\hline$n$ & 13,195 & 11,588 & 1,607 & 11,972 & 1,0691 & 1,281 & 11,504 & 1,691 & 10,246 & 1,333 \\
\hline \multirow{2}{*}{\multicolumn{11}{|c|}{ Venous, YSI }} \\
\hline$<100 \mathrm{mg} / \mathrm{dL}$ & & & & & & & & & & \\
\hline MAD (mg/dL) & - & - & 13.4 & - & - & 12.6 & - & - & - & 10.2 \\
\hline$n$ & - & - & 1,475 & - & - & 1,327 & - & - & - & 620 \\
\hline \multicolumn{11}{|l|}{$\geq 100 \mathrm{mg} / \mathrm{dL}$} \\
\hline MARD (\%) & - & - & 11.4 & - & - & 10.3 & - & - & - & 10.9 \\
\hline$n$ & - & - & 10,697 & - & - & 8,789 & - & - & - & 9,722 \\
\hline \multicolumn{11}{|l|}{ All } \\
\hline$\%$ & - & - & 12.0 & - & - & 11.0 & - & - & - & 11.0 \\
\hline$n$ & - & - & 12,172 & - & - & 10,116 & - & - & - & 1,0342 \\
\hline
\end{tabular}

${ }^{a}$ Excluding rapidly changing/hypoglycemia $(80 \mathrm{mg} / \mathrm{dL})$ and impending hypoglycemia.

$\mathrm{BG}$, blood glucose; MAD, mean absolute difference, MARD, mean absolute relative difference.

is provided in Table 2. The variation in MARD against BG reference for different sensors is shown in Figure 2, with the linear mixed model estimating the between-subjects variance component to be $44 \%$ of the total variation. There was no significant difference between left and right arm insertion sites $(11.2 \%$ and $11.4 \% ; P=0.5950)$.
The System's sensor results were highly correlated to capillary BG. Regression analysis produced a slope of 1.02 , an intercept of $-6.4 \mathrm{mg} / \mathrm{dL}$, and a correlation coefficient of 0.95 (range, $23-498 \mathrm{mg} / \mathrm{dL}$ ). The coefficient of variation of sensitivity (as measured by slope) between sensors was $8.5 \%$, $8.6 \%$, and $8.9 \%$ for each sensor lot. This variation was

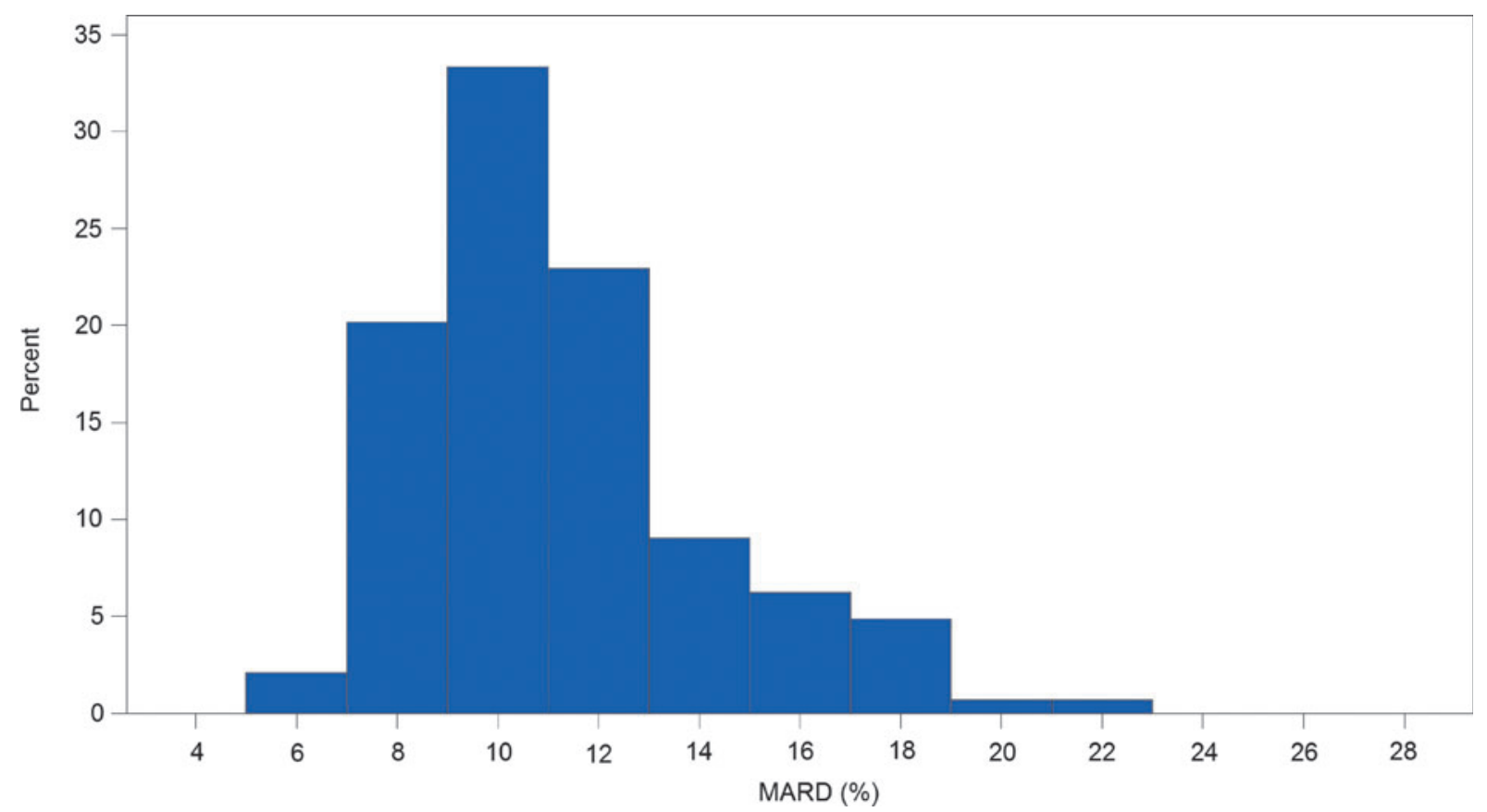

FIG. 2. Histogram of the mean absolute relative difference (MARD) per sensor. 
predominantly due to between-sensor variance, with the linear mixed model estimating the between-subjects variance component to be $37 \%$ of the total. There were no statistically significant differences in sensor sensitivity (i.e., slope) between insertion sites on either the right or left arm $(P=0.5542)$.

Performance of the System was stable across the 14 days of wear after the first day. The percentage of readings within Consensus Error Grid Zone A (BG reference) on Days 2, 7 , and 14 was $88.4 \%, 89.2 \%$, and $85.2 \%$, respectively (Fig. 3), and the MARD on the same days was $11.9 \%, 10.9 \%$, and $10.8 \%$, respectively.

The mean time to first glucose results was $1 \mathrm{~h} 1 \mathrm{~min}$ $(n=168)$, and $100 \%$ of sensors were able to provide interstitial glucose results within $1 \mathrm{~h} 10 \mathrm{~min}$ after insertion. The mean lag time between the System sensor and YSI reference was $4.5 \pm 4.8 \mathrm{~min}$.

Sensor accuracy was not affected by factors such as body mass index (BMI), age, type of diabetes, clinical site, insulin administration, or hemoglobin A1c, as the percentages of readings within Consensus Error Grid Zone A were similar (Fig. 4).

At Days 1 and 15, study participants completed a questionnaire specific to this study and rated their experience with the System on a scale of 0 (strongly agree) to 4 (strongly disagree) for several subjective categories. On Day 1, the scorecard included seven statements about ease of use, pain compared with fingerstick, adequacy of packaging information, and pain or bleeding when applying the sensor to either arm. On Day 15, the scorecard included nine statements about the sensor relative to comfort of wear, ease of wear, whether the sensor got in the way of daily activities, pain compared with fingerstick, easier than fingerstick, and erythema or edema after removal of sensor from either arm. A score of 0,1 , or 2 was considered a favorable response. On Day 1, favorable ratings were reported by most respondents ( $\geq 97.2 \% ; n=72$ ) for seven of seven subjective statements.

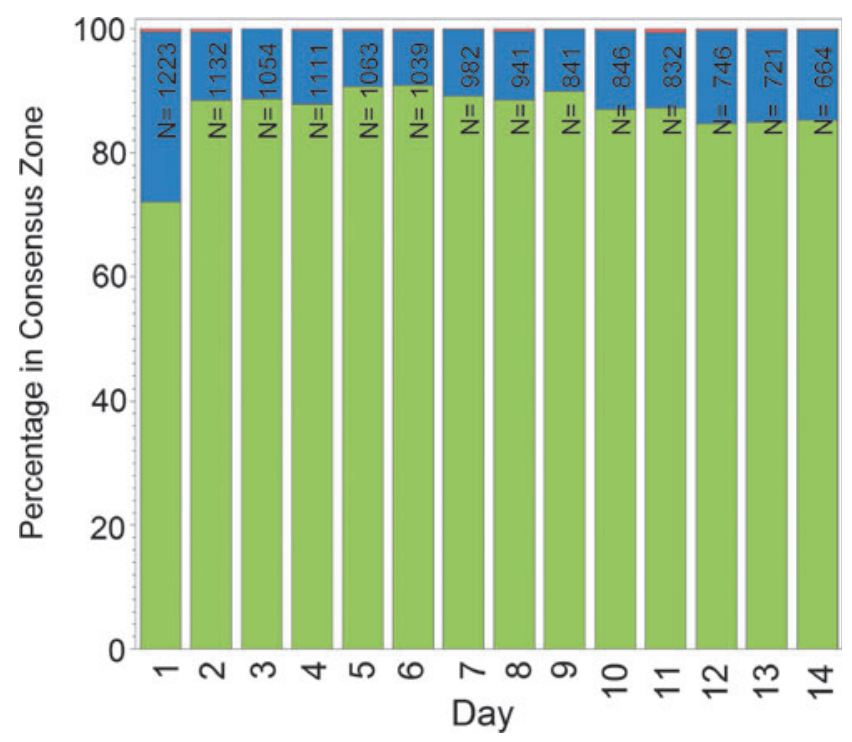

FIG. 3. Stability of accuracy across 14 days of Freestyle Libre sensor wear: Consensus Error Grid Zone A (green), Zone B (blue), and Zone C (red). $N$ is the number of paired sensor and reference data points per day of wear for all sensors used in the study.
Likewise, on Day 15 the majority of respondents ( $\geq 94.4 \%$; $n=72$ ) reported favorable ratings for nine of nine subjective statements.

In total, $98.6 \%$ (142/144; both arms of 72 respondents) of responses were favorable ratings of $\leq 2$ for the statement "The amount of pain I felt when applying the Sensor was acceptable." A favorable response of $\leq 2$ was also reported by $99.3 \%(143 / 144)$ of responses for statement "The amount of bleeding I experienced when applying the Sensor was acceptable."

There were no unexpected adverse device effects reported during the clinical study. One participant had a serious adverse event (severe hypoglycemia prior to sensor insertion) not related to the study or device. Skin issues observed in 202 site exams of 72 study participants were as follows: moderate to severe itching $0.5 \%$ of the time, moderate erythema $4.0 \%$ of the time, and $98.6 \%$ of the insertions had a pain rating of $\leq 2$. Rate of mild incidences was $<9 \%$ for any individual category of skin issues mentioned above, including edema, rash, induration, bruising, bleeding, and others.

\section{Discussion}

This study evaluated the performance and usability of the FreeStyle Libre system. Study results showed agreement between the System's sensor readings and capillary BG and venous reference. The capillary BG reference provided a wider distribution of glucose results and covered up to 14 days of wear. Therefore, capillary BG was used as the primary comparator for the System's performance evaluation. Capillary BG reference provides more reference points and represents real-life accuracy during daily patient use. One strip lot was used as the capillary BG reference across all clinical sites and sensor lots so there were adequate data to determine variation between sensor lots and sites without confounding results with multiple strip lots.

The System is unique among existing interstitial glucose monitoring technologies in that the wired enzyme factoryonly calibrated sensor has wear time of up to 14 days without additional calibration. This lack of reliance on an external BG monitor for calibration is a potential advantage as errors in BG meters could potentially lead to glucose monitoring system errors. Sensors requiring routine user calibration several times daily can be affected by glucose instability, such as observed postprandially. ${ }^{15}$ Sensor delays or lag between interstitial readings and venous or capillary readings have also been shown to vary among sensors, ${ }^{16}$ with newergeneration sensors demonstrating less lag time. ${ }^{15,17,18}$

Differences among interstitial, ${ }^{14,19,20}$ capillary, and venous readings must also be considered when comparing accuracy outcomes., ${ }^{90,21-23}$ Sources contributing to differences between capillary BG versus venous YSI readings include the amount of blood used for testing, delays in analysis from the time of sampling, and differences in the composition of the blood samples., ${ }^{9,10}$

Collectively, these differences limit the direct comparison of accuracy outcomes among sensor technologies. Therefore, the present study was compared with reported outcomes with similar wired enzyme technology, factory-calibrated sensors, and those reporting accuracy outcomes using Consensus EGA. In a study of 55 subjects who wore a wired enzyme, 
A
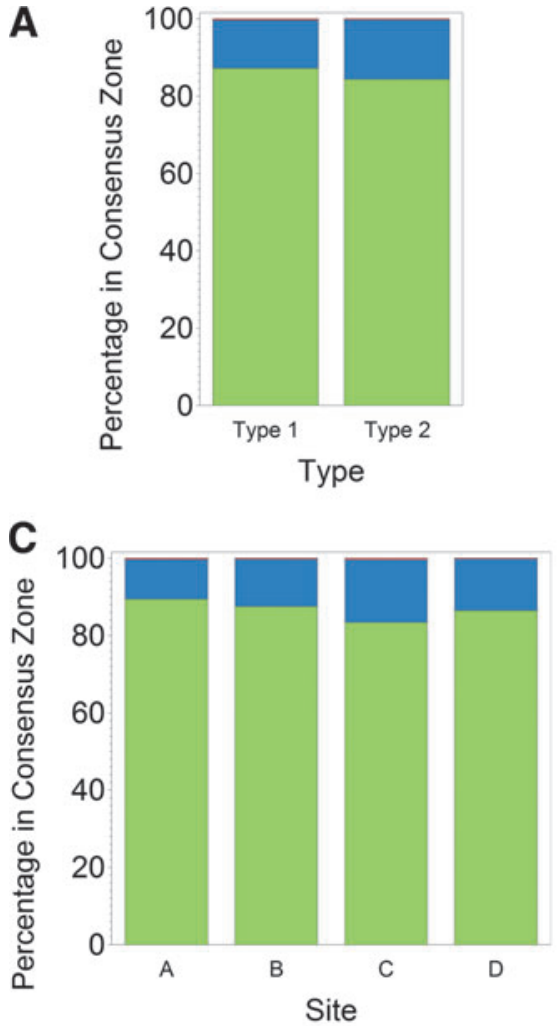

E

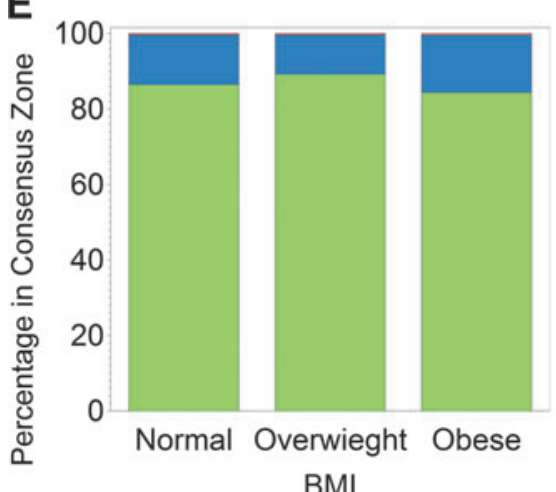

G

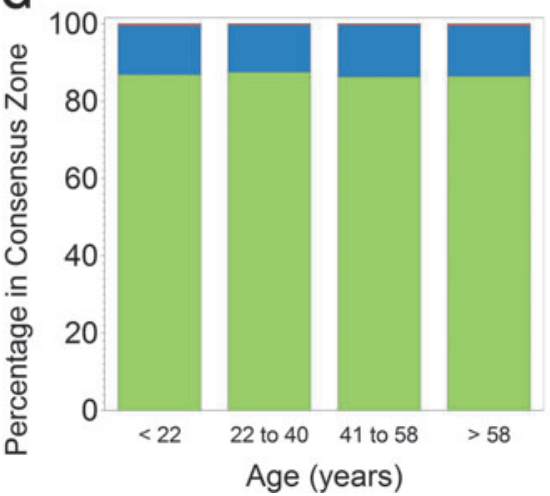

B

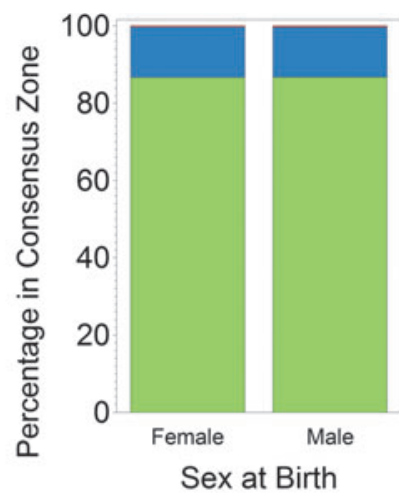

D

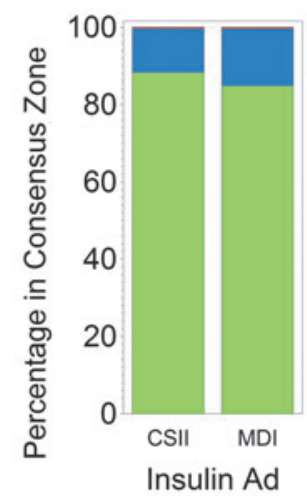

$\mathbf{F}$

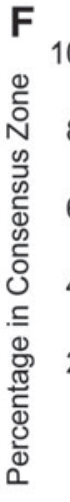

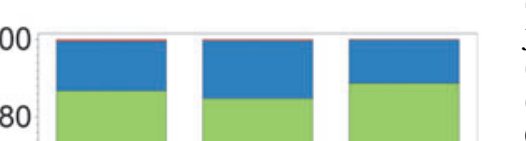

60

40

40

20

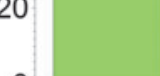

$<7.0 \%$

$7.0-8.5 \% \quad>8.5 \%$

$\mathrm{HbA1c}$

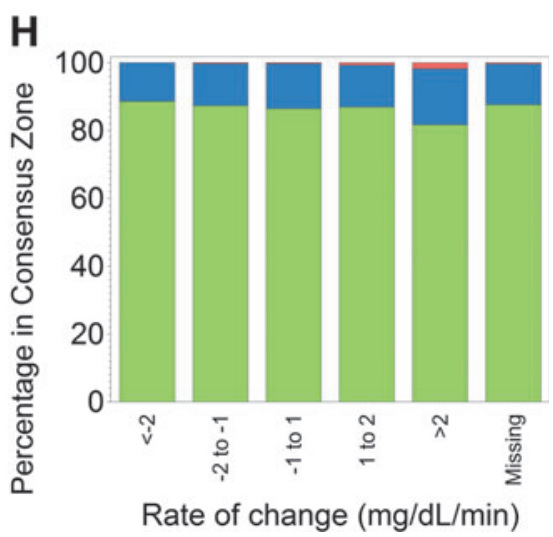

FIG. 4. Accuracy of the FreeStyle Libre sensor as a function of various factors or patient characteristics: (A) diabetes type, (B) sex, (C) insertion site, (D) insulin administration (Insulin Ad) (continuous subcutaneous insulin infusion [CSII] or multiple daily insulin injections $[\mathrm{MDI}]),(\mathbf{E})$ body mass index (BMI), (F) hemoglobin Alc (HbAlc), (G) age, and (H) rate of change. Consensus Error Grid zones were Zone A (green), Zone B (blue), and Zone C (red). factory-calibrated sensor for up to 14 days, results demonstrated MARD of $12.2 \%$, with $88.0 \%$ of sensor readings within Zone A of Consensus EGA and minimal change in sensor sensitivity over the 14-day wear time. ${ }^{24}$ Similarly, another study evaluating the feasibility of a factory-calibrated sensor using wired enzyme technology for 5 days demonstrated a MARD of $13.4 \%$, and $83.5 \%$ of readings were within Zone A of Consensus EGA. ${ }^{25}$ Results from those published studies were consistent with the outcomes in the present study. Accuracy of the System was similar across 14 days of sensor 
wear with the exception of the first day of wear, which had the lowest accuracy (Consensus EGA showed $72.0 \%$ in Zone A for Day 1 compared with $88.4 \%$ in Zone A for Day 2). This may be due in part to the body's natural inflammatory response to sensor insertion, which has been shown to affect glucose concentration in interstitial fluid. ${ }^{26}$

In the present study, the System's sensor did not show any marked differences in accuracy outcomes relative to BMI, age, type of diabetes, clinical site, insulin administration, or hemoglobin A1c. In comparison, the accuracy (Clarke EGA) of the FreeStyle Navigator ${ }^{\circledR}$ sensor (Abbott Diabetes Care), which used a sensor with the same wired enzyme technology, as reported by Weinstein et al., ${ }^{27}$ did not differ as a function of age, sex, ethnicity, years since diagnosis of diabetes, or sensors worn on either the arm or abdomen but differed depending on the subject's BMI. The percentage of readings in Zone A (Clarke EGA) for participants who had a BMI of $<25 \mathrm{~kg} / \mathrm{m}^{2}$ was $78.8 \%$ compared with $84.4 \%$ for participants with a BMI of $>30 \mathrm{~kg} / \mathrm{m}^{2}$, which the authors suggested could have been attributed to differences in blood flow relative to subcutaneous adipose tissue thickness. The present study with the System included a broad range of BMI (18.7$47.2 \mathrm{~kg} / \mathrm{m}^{2}$ ), which did not affect the sensor accuracy. Placement of the System's sensor was on both arms for each subject, and future studies could evaluate the effects of sensor accuracy in different locations on the body.

These results have clinical implications for individuals with diabetes and for the clinicians who treat them. Several randomized controlled studies have revealed better hemoglobin A1c outcomes associated with the frequency of sensor wear. $^{28-32}$ Thus, a sensor with a longer wear period that does not require fingerstick calibration with its associated burden and pain may support more frequent sensor use with improved glycemic outcomes. This system with no additional fingerstick may also benefit groups that have demonstrated poor adoption of persistent sensor use.

The System's sensor provides a broader interval and volume of measurements, including day and night readings, which can be used to evaluate glucose patterns and trends. In comparison, capillary BG readings provide single, intermittent measurements, which may not capture intervals of extreme variability or nocturnal events. In a recent study, it was demonstrated that the use of continuous glucose monitoring with or without alarms reduces time spent outside glucose targets compared with self-monitoring of BG. ${ }^{13}$ The System provides the user with the current glucose result, glucose pattern, and trend information on the display of the hand-held reader when the sensor is scanned. This type of monitoring system may benefit individuals who have ceased sensor use due to alarm fatigue, becoming overwhelmed by alarms. ${ }^{11}$ Limitations of the current study are single body site used for data collection, limited venous reference data over the 14-day wear due to practical limitation of obtaining blood, and a limited number of sensor lots used in the study. Further research is needed to evaluate whether the System could provide additional benefits such as improvement in glycemic outcomes with continued use over time, as well as improved compliance with sensor wear.

\section{Conclusions}

In this prospective study, the performance of the factoronly calibrated FreeStyle Libre Flash glucose monitoring system was demonstrated by the accuracy of sensor readings and the stability of accurate readings over 14 days of use. The accuracy of the System was unaffected by subject characteristics, making it suitable for a broad range of individuals. Under normal conditions, the System provides an easy to use and comfortable sensor wear experience for up to 14 days without the need for fingerstick measurements. It is anticipated that the provision of comprehensive glucose data for up to 14 days with reduced pain and burden for the end user will support enhanced diabetes management.

\section{Acknowledgments}

The authors thank Joe Bugler for his critical review of the manuscript and Zoe K. Welsh for graphical and statistical support. Suzie Webster (ConsignMed, Inc.) provided medical writing and editorial assistance. Funding for this study was provided by Abbott Diabetes Care.

\section{Author Disclosure Statement}

S.A. is an employee of Abbott Diabetes Care. M.P.C., L.J.K., T.B., and B.W.B. were the study investigators and declare that no competing financial interests exist.

\section{References}

1. Freckmann G, Pleus S, Link M, Zshornack E, Klotzer H, Haug C: Performance evaluation of three continuous glucose monitoring systems: comparison of six sensors per subject in parallel. J Diabetes Sci Techol 2013;7:842-853.

2. Pfützner A, Mitri M, Musholt PB, Sachsenheimer D, Borchert M, Yap A, Forst T: Clinical assessment of the accuracy of blood glucose measurement devices. Curr Med Res Opin 2012;28:525-531.

3. Freckmann G, Baumstark A, Schmid C, Pleus S, Link M, Haug C: Evaluation of 12 blood glucose monitoring systems for self-testing: system accuracy and measurement reproducibility. Diabetes Technol Ther 2014;16:113-122.

4. Klaff LJ, Brazg R, Hughes K, Tideman AM, Schachner HC, Stenger P, Pardo S, Dunne N, Parkes JL: Accuracy evaluation of Contour Next compared with five blood glucose monitoring systems across a wide range of blood glucose concentrations occurring in a clinical research setting. Diabetes Technol Ther 2015;17:8-15.

5. Thomas LE, Kane MP, Bakst G, Busch RS, Hamilton RA, Abelseth JM: A glucose meter accuracy and precision comparison: the FreeStyle Flash versus the Accu-Chek Advantage, Accu-Chek Compact Plus, Ascensia Contour, and the BD Logic. Diabetes Technol Ther 2008;10:102110.

6. Damiano E, El-Khatib F, Zheng H, Nathan D, Russell S: A comparative effectiveness analysis of three continuous glucose monitors. Diabetes Care 2013;36:251-259.

7. Damiano E, McKeon K, El-Khatib F, Zheng H, Nathan D, Russell S: A comparative effectiveness analysis of three continuous glucose monitors: the Navigator, G4 Platinum, and Enlite. J Diabetes Sci Technol 2014;8:699-708.

8. Matuleviciene V, Joseph J, Andelin M, Hirsch I, Attvall S, Pivodic A, Dahlqvist, Klonoff D, Haraldsson B, Lind M: A clinical trial of the accuracy and treatment experience of the Dexcom G4 sensor (Dexcom G4 system) and Enlite sensor (Guardian REAL-Time system) tested simultaneously in ambulatory patients with type 1 diabetes. Diabetes Technol Ther 2014;16:759-767. 
9. Kuwa K, Nakayama T, Hoshino $T$, Tominaga M: Relationships of glucose concentrations in capillary whole blood, venous whole blood and venous plasma. Clin Chim Acta 2001;307:187-192.

10. Tonyushkina K, Nichols JH: Glucose meters: a review of technical challenges to obtaining accurate results. J Diabetes Sci Technol 2009;3:971-980.

11. Shivers JP, Mackowiak L, Anhalt H, Zisser H. "Turn it off!": diabetes device alarm fatigue considerations for the present and the future. J Diabetes Sci Technol 2013;7:789-794.

12. Rossetti P, Bondia J, Vehí J, Fanelli CG: Estimating plasma glucose from interstitial glucose: the issue of calibration algorithms in commercial continuous glucose monitoring devices. Sensors (Basel) 2010;10:10936-10952.

13. New JP, Ajjan R, Pfeiffer AFH, Freckmann G: Continuous glucose monitoring in people with diabetes: the randomized controlled Glucose Level Awareness in Diabetes Study (GLADIS). Diabet Med 2015;32:609-617.

14. Rebrin K, Sheppard NF Jr, Steil GM: Use of subcutaneous interstitial fluid glucose to estimate blood glucose: revisiting delay and sensor offset. J Diabetes Sci Technol 2010; 4:1087-1098.

15. Castle JR, Ward WK: Amperometric glucose sensors: sources of error and potential benefit of redundancy. J Diabetes Sci Technol 2010;4:221-225.

16. Mazze RS, Strock E, Borgman S, Wesley D, Stout P, Racchini J: Evaluating the accuracy, reliability, and clinical applicability of continuous glucose monitoring (CGM): is CGM ready for real time? Diabetes Technol Ther 2009;11: 11-18.

17. Bailey T, Zisser H, Chang A: New features and performance of a next-generation SEVEN-day continuous glucose monitoring system with short lag time. Diabetes Technol Ther 2009;11:749-755.

18. Michaud C, Cengiz E, Tamborlane WV, Carria LR, Weinzimer SA: Warming up to sensors: does site warming improve continuous glucose monitoring performance? [abstract]. Diabetes 2014;63(Suppl 1):870-P.

19. Cengiz E, Tamborlane VW: A tale of two compartments: interstitial versus blood glucose monitoring. Diabetes Technol Ther 2009;11(Suppl 1):S-11-S-16.

20. Lodwig V, Heinemann L; Glucose Monitoring Study Group: Continuous glucose monitoring with glucose assessment criteria. Diabetes Technol Ther 2003;5:572-586.

21. Kempe K, Price D, Ellison J, Marhoul J, Morrow L, Win K, Kuschma K, Hompesch M: Capillary and venous blood glucose concentrations measured during intravenous insulin and glucose infusion: a comparison of steady and dynamic states. Diabetes Technol Ther 2009;11:669-674.

22. Colaguri S, Sandbaek A, Carstensen B, Christensen J, Glumert C, Lauritzen T, Borch-Johnsen K: Comparability of venous and capillary glucose measurements in blood. Diabet Med 2003;20:953-956.
23. Clinical and Laboratory Standards Institute: Glucose Monitoring in Settings Without Laboratory Support; Approved Guideline-Second Edition. CLSI document AST4-A2 Wayne, PA: Clinical and Laboratory Standards Institute, 2005.

24. Hoss U, Budiman ES, Liu H, Christiansen MP: Continuous glucose monitoring in the subcutaneous tissue over a 14day sensor wear period. J Diabetes Sci Technol 2013;7: 1210-1219.

25. Hoss U, Budiman ES, Liu H, Christiansen MP: Feasibility of factory calibration for subcutaneous glucose sensors in subjects with diabetes. J Diabetes Sci Technol 2014;8:89-94.

26. Ward KW: A review of the foreign-body response to subcutaneously-implanted devices: the role of macrophages and cytokines in biofouling and fibrosis. J Diabetes Sci Technol 2008;2:768-777.

27. Weinstein RL, Schwartz SL, Brazg RL, Bugler JR, Peyser A, McGarraugh GV: Accuracy of the 5-Day FreeStyle Navigator continuous glucose monitoring system. Diabetes Care 2007;30:1125-1130.

28. JDRF Continuous Glucose Monitoring Study Group: The effect of continuous glucose monitoring in well-controlled type 1 diabetes. Diabetes Care 2009;32:1378-1383.

29. Danne T, de Valk HW, Kracht KW, Geldmacher R, Sölter L, von dem Berge W, Welsh ZK, Bugler JR, Lange K, Kordonouri $\mathrm{O}$ : Reducing glycaemic variability in type 1 diabetes self-management with a continuous glucose monitoring system based on wired enzyme technology. Diabetologia 2009; 52:1496-1503.

30. Hirsch IB, Abelseth J, Bode BW, Fischer JS, Kaufman FR, Mastrototaro J, Parkin CG, Wolpert HA, Buckingham BA: Sensor-augmented insulin pump therapy: Results of the first randomized treat-to-target study STAR-1. Diabetes Technol Ther 2008;10:377-383.

31. Bergenstal RM, Tamborlane WV, Ahmann A, Buse JB, Dailey G, Davis SN, Joyce C, Peoples T, Perkins BA, Welsh JB, Willi SM, Wood MA; STAR 3 Study Group: Effectiveness of sensor-augmented insulin-pump therapy in type 1 diabetes. N Engl J Med 2010;363:311-320. Erratum in N Engl J Med 2010;363:1092.

32. Battelino T, Phillip M, Bratina N, Nimri R, Oskarsson P, Bolinder $\mathrm{J}$ : Effect of continuous glucose monitoring on hypoglycemia in type 1 diabetes. Diabetes Care 2011;34: 795-800.

Address correspondence to:
Shridhara Alva, PhD
Clinical Affairs
Abbott Diabetes Care
1360 South Loop Road
Alameda, CA 94502

E-mail: Shridhara.alva@abbott.com 